\title{
Heart failure is common in diabetic cats: findings from a retrospective case-controlled study in first-opinion practice
}

ObJectives: To study the prognosis and cause of death in cats with diabetes mellitus.

Methods: Twenty consecutive cases of feline diabetes mellitus diagnosed in first-opinion practice were followed. Three control cats, without diabetes, were matched to each case of diabetes; these were also followed.

Results: One Somali cat with diabetes could not be matched, so complete data analysis considered only 19 diabetics and 57 matched controls. Death occurred in 14 of 20 diabetics and 23 of 57 controls although one control cat was eventually lost to follow-up. Heart disease and heart failure led to death in six diabetic cats. One of these was the non-matched Somali; nevertheless, the death rate from heart disease in the diabetics was five of 19 compared with two of 57 in controls. The relative risk of heart failure in diabetic cats was 10.4 times that of the controls; this difference in rates was statistically significant. Survival amongst diabetics was significantly worse than for controls. For the control cats median survival was $\mathbf{7 1 8}$ days after the index visit, whereas for the diabetic cases median survival was $\mathbf{3 8 5}$ days after diagnosis.

Clinical Significance: Heart disease and failure are common in diabetic cats. This observation deserves further attention.

Barton Veterinary Hospital, 34 New Dover Road Canterbury, CT1 3BH Kent

*Department of Statistics and Modelling Science, University of Strathclyde, Glasgow G1 1XD

\section{INTRODUCTION}

Diabetes mellitus is common in the cat and the prevalence of this condition appears to be increasing (Peterson 1998, Rand and Marshall 2004, Rand and others 2004). The prognosis for cats with diabe tes mellitus in first opinion practice has received little attention in the literature; few data indicate why diabetic cats die. Death in people with diabetes is over whelmingly because of cardiovascular dis ease (Grundy and others 1999, Almdal and others 2004, Bell 2004, Bertoni and others 2004, Nichols and others 2004).
Experimental induction of diabetes mel litus in various laboratory mammals also causes cardiovascular disease and heart failure so that the prevalence of cardiac disease and failure in diabetic cats seemed worthy of examination. The purpose of this study was to examine the progno sis and cause of death for a cohort of con secutive cases of feline diabetes mellitus diagnosed in a first opinion veterinary practice, and to compare these with con trol cats matched for age, breed and sex.

\section{MATERIALS AND METHODS}

\section{Selection of cases}

The computer records of Barton Veteri nary Hospital (BVH) were searched for all cases of feline diabetes first diagnosed during a six year period between June 1999 and June 2005. Searching was achieved by identifying all cats for which a fructosamine assay had been performed, and/or where insulin therapy, or oral hypoglycaemic medication, and/or a diet designed for use with feline diabetes had been dispensed. These raw records were then reviewed in detail to identify cases, which were confirmed as diabetic based on compatible clinical signs, concurrent hyperglycaemia and glycosuria, or concur rent elevated fructosamine levels, or both. These records were further sorted to iden tify those cases, which had been diagnosed in the first opinion stream of the practice and treated under our care thereafter.

\section{Selection of controls}

For each case of diabetes diagnosed according to these criteria, three matched non diabetic control cats were sought by the following routine. The date of diagno sis of each diabetic was identified together with their breed, sex and age on that date. The hospital database was searched for matching control cats of the same age (to the nearest year), breed and sex which 
had been seen at the hospital, either for a routine vaccination or a new episode of illness, within a maximum of 90 days before or after the date of diagnosis of the index diabetic case. If more than three control cases were found, three control cases were chosen at random.

\section{RESULTS}

\section{Diabetic cats}

A total of 28 cats with a new diagnosis of diabetes were examined and treated at $\mathrm{BVH}$ during the six year period in ques tion. Of these 28 cats, six were excluded from further detailed analysis because their condition was originally diagnosed elsewhere and the cats were referred to our second opinion service and/or their condition was managed at another prac tice subsequent to the cat being seen at our practice. Another two cats had both diabetes and hyperthyroidism. These cases were also excluded from further analysis. The remaining 20 cats were the subject of this study.

All cats diagnosed as diabetic exhibited marked and persistent hyperglycaemia and glycosuria at the time of diagnosis as well as compatible clinical signs. The principal clinical signs recorded from these animals were: polydipsia/polyuria (80 per cent), weight loss (75 per cent), polyphagia (65 per cent), depression/leth argy (25 per cent), capricious/variable appetite ( 15 per cent), dysuria/haematuria (15 per cent) and peripheral neuropathy (10 per cent). Following routine haema tology, biochemistry and urinalyses, other laboratory tests were frequently used in the evaluation of these diabetic cats; those tests used most frequently were: fructosamine assays for diagnosis and/or monitoring (in 75 per cent of cases), serial glucose curves (70 per cent of cases) and measure ments of thyroid hormone ( 50 per cent of cases). Systemic arterial blood pressure was not measured in these cats.

The 20 cats consisted of 15 domestic shorthairs (DSH), four domestic longhairs (DLH) and one Somali cat. Males out numbered females (13:7); all were neu tered. Most cats were middle aged or older at the time of diagnosis (range six to 16 years). Median age at diagnosis was 12 years.

We were unable to find any matching control cats for the male Somali cat (case 16), consequently this cat was excluded from the case control study for which only 19 diabetic cats were thus eligible.

Control cats $(n=57)$ consisted of 45 DSH and 12 DLH. The sex ratio of these cats was identical to the diabetic cases (36 males, 21 females) and again all were neu tered. Age structure of the control group strongly resembled the age of the cases (range five to 16 years, median 11.5 years).

\section{Treatment and clinical outcomes of the diabetic cases}

At the time of writing, of these 20 diabetic cats, 14 were dead and six were still alive. The cause(s) to which death or euthanasia was ascribed are given in Table 1 . Of the 14 cats that died, six were caused by heart failure. Details of the clinical and labora tory findings which confirmed the pres ence of heart failure in these cats are given in Tables 2 and 3.

One cat was euthanased, without treat ment, three days after diagnosis (case 15). Most of the cats that were treated eventu ally received insulin therapy $(\mathrm{n}=17)$ and a diet particularly designed for diabe tic cats $(\mathrm{n}=11)$ (Hills Feline W/D $\mathrm{n}=6$, Hills Feline M/D $n=5)$. However, some of the cats were initially treated with an oral hypoglycaemic agent (glipizide, see

\section{Table 1. Causes of death in the 14 diabetic cats which have died}

\begin{tabular}{|c|c|c|c|c|}
\hline Cause of death/euthanasia & Numbers & Cases & Details of diagnostic findings & Other information \\
\hline Heart failure & $6 / 14$ & $2,4,7,10,13,16 *$ & See Tables 2 and 3 & $\begin{array}{l}\text { One died, } \\
\text { five euthanased }\end{array}$ \\
\hline \multirow[t]{3}{*}{$\begin{array}{l}\text { Poor diabetic } \\
\text { control: "unstable", }\end{array}$} & $2 / 14$ & 9,12 & $\begin{array}{l}\text { Persistent/frequent hyperglycaemia } \\
\text { and glycosuria }\end{array}$ & 2 euthanased \\
\hline & & & Elevated fructosamine & $\begin{array}{l}\text { One (12) treated } \\
\text { with glipizide only }\end{array}$ \\
\hline & & & $\begin{array}{l}\text { Owners persisted with treatment for } \\
17 \text { (case 9) and } 16 \text { months } \\
\text { (case 12) respectively. }\end{array}$ & $\begin{array}{l}\text { Other (9) treated } \\
\text { with PZI insulin } \\
\text { once a day }\end{array}$ \\
\hline Hypoglycaemia with convulsions & $1 / 14$ & 19 & $\begin{array}{l}\text { Hypoglycaemia. Neurological signs } \\
\text { persisted after euglycaemia } \\
\text { was achieved }\end{array}$ & $\begin{array}{l}\text { Euthanased } \\
\text { Owner, a doctor, } \\
\text { was managing this } \\
\text { cat's diabetes herself }\end{array}$ \\
\hline $\begin{array}{l}\text { Owner requested } \\
\text { euthanasia without treatment }\end{array}$ & $1 / 14$ & 15 & & $\begin{array}{l}\text { Euthanased } \\
\text { (three days after } \\
\text { diagnosis) }\end{array}$ \\
\hline Profound anaemia & $1 / 14$ & 14 & Investigation not permitted by owner & Euthanased \\
\hline Sudden death & $1 / 14$ & 8 & $\begin{array}{l}\text { Glycaemic control being attempted } \\
\text { with glipizide }\end{array}$ & Died \\
\hline
\end{tabular}

*This cat was a male Somali and no matched controls were available. It was omitted from the case-control analyses 


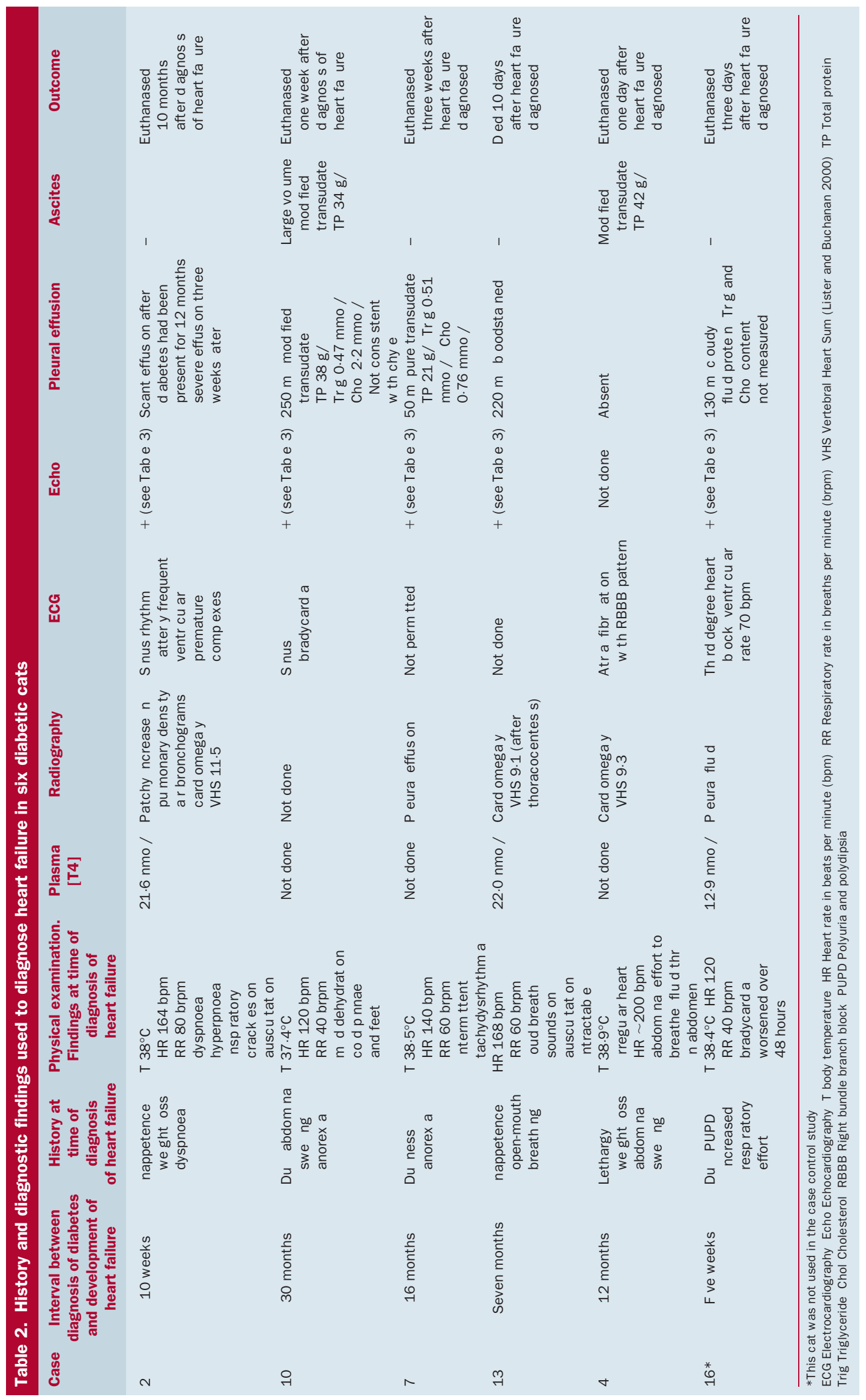




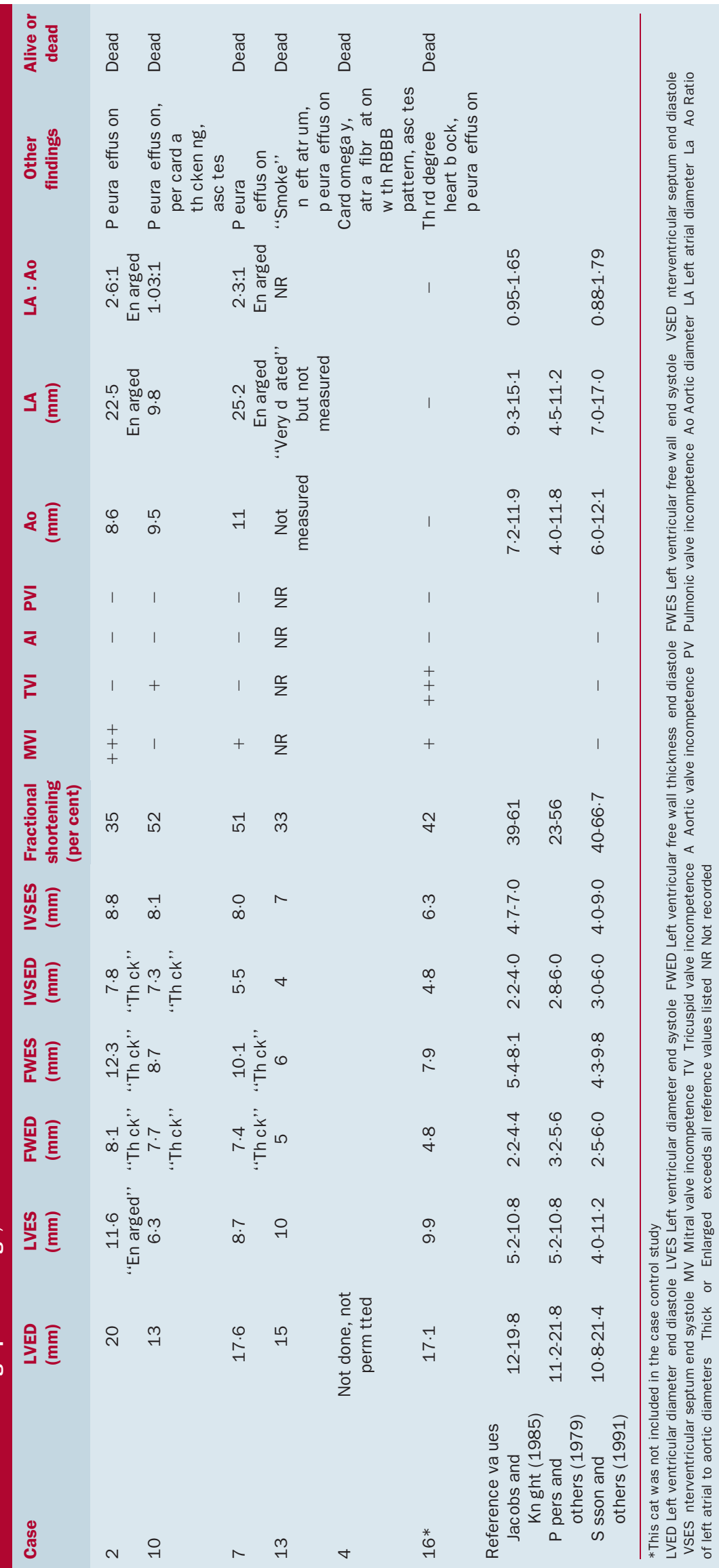


below). Insulin therapy most frequently consisted of Lente insulin given twice daily. Insulin dose was adjusted based on plasma glucose curves and fructosamine assays in most cases. Maximum dose of insulin recorded was six units twice daily. Of the cats treated with insulin, four of 17 had insulin therapy withdrawn at some time because the requirement for exogenous insulin therapy eventually disappeared; in three of these cases insulin therapy had to be reinstituted some months later.

Glipizide (2.5 to $5.0 \mathrm{mg}$ twice a day) was used initially to treat several cats $(n=6)$ but this resulted in poor glycaemic control in five cases, one of which died suddenly (case 8; Table 1). One cat treated in this way developed diabetic hyperosmolar syndrome (case 3) and another developed severe dehydration, azotaemia and ketoacidosis with hypoka laemia (case 11). Four of these cats initially treated with glipizide were eventually trea ted with insulin. One cat receiving glipi zide exhibited fair control of glycaemia for many months, but eventually, because of unstable blood glucose levels and ongo ing clinical signs, this cat was euthanased at the owner's request (case 12; Table 1).

\section{Control cats' clinical outcomes}

At the time of writing, 23 of the control cats are known to have died and 33 are known to be still alive. One of these con trol cats has been lost to follow up. Of the 23 deaths in this group, seven were attributed to chronic renal disease, four to neoplasia (mammary adenocarcinoma, squamous cell carcinoma of the mouth, salivary gland carcinoma and undiagnosed neoplasm of the lower bowel), four were attributed to hyperthyroidism (in two cases complicated by other conditions; cholangiohepatitis and recurrent idio pathic cystitis) and two to heart failure. For the cats where heart failure was diag nosed, details of the clinical and labora tory findings, which confirmed the presence of heart failure in these cats are given in Table 4. Various other abnormal ities were listed as the immediate cause of death or euthanasia in one control case each (road traffic accident, feline immunodeficiency virus, chronic abscess, undifferentiated anaemia with hypoalbu minaemia). In two control cases that were euthanased, no diagnosis was recorded. Neither of these cats was showing signs attributable to cardiovascular or respira tory disease.

\section{Data management and statistical analyses}

Information on each of the 19 eligible cases and their three matched controls was classified according to heart disease (presence or absence), survival outcome (alive or dead at the end of the study), sur vival time since diagnosis (days), sex (male or female neuter), age (years) and breed (DSH or DLH).

Cases and controls were compared using binary logistic regression to identify which factors were associated with (i) the risk of heart disease and (ii) the risk of mortality during the course of the study. Factors found not to be significant were retained as forced covariates within the model after investigating the stability of fitting other models with and without each factor. Two factor interactions between fitted factors were examined. Results con sisting of the odds ratios, 95 per cent confidence intervals (CI) and statistical significance of the final models were obtained.

In addition, survival analysis and the Weibull distribution model were used to identify those factors and their 95 per cent CI which significantly influenced how long case and control cats lived following recruitment. As some cats were still alive following the end of the study, the data were adjusted for censored observations.

Data were summarised using classifica tion tables and a box plot used to compare the distribution of life times of cases and controls.

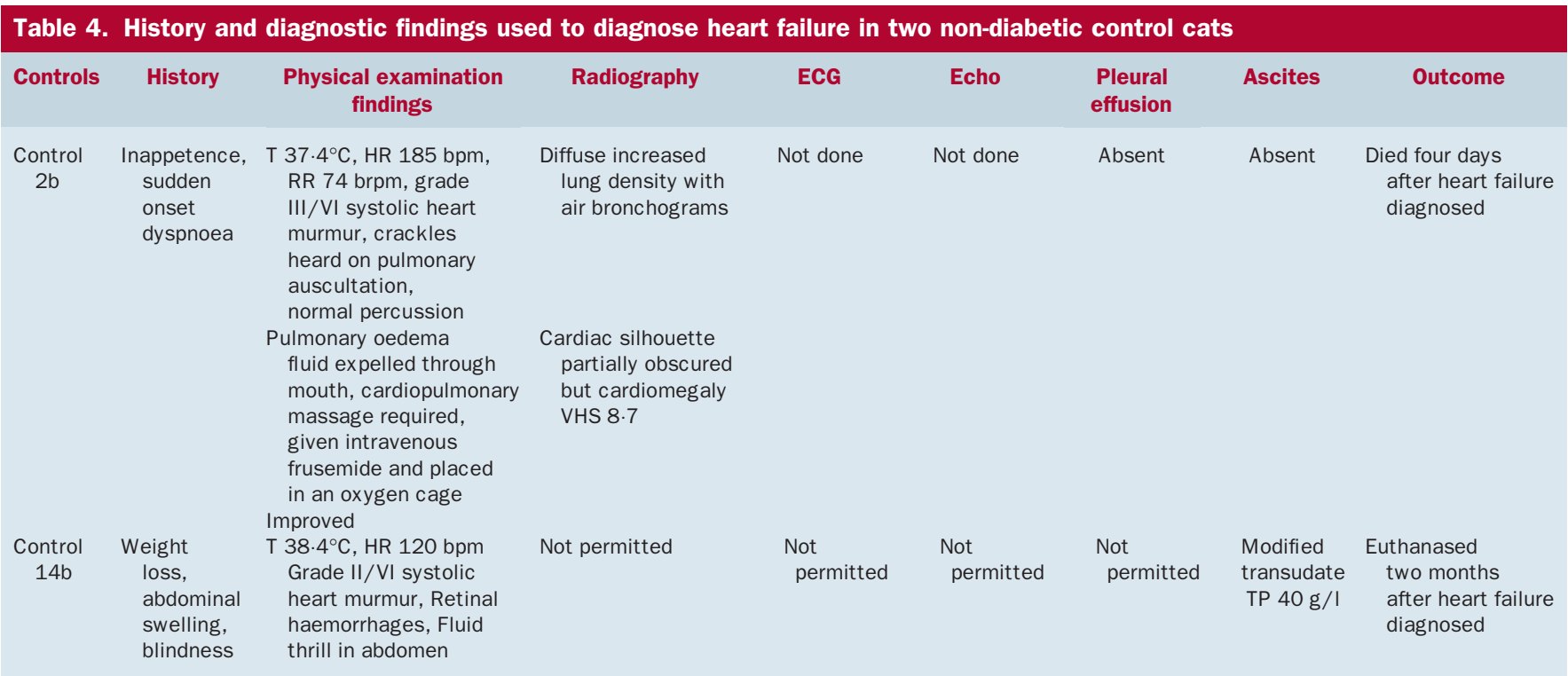


Statistical analyses were undertaken using Minitab version 14 statistical soft ware and $P$ values less than 0.05 were con sidered to be significant.

\section{Results of statistical evaluation}

Table 5 shows the incidence of heart dis ease and the frequency of survival found for diabetic cases and non diabetic control cats. The proportion of diabetic cats with heart disease in the case control study was five of 19 (26.3 per cent) compared with the lower rate of two of 57 ( 3.5 per cent) for controls. Similarly, the mortality rate amongst diabetic cats was 13 of 19 (68.4 per cent), which was much higher than that for controls at 23 of $57(40.4$ per cent). As to be expected, there was lit tle difference in the proportions of cats of different sex and breeds between diabetic and non diabetic cats in view of the con trols being selected to match cases. The mean ages of cases and controls were 11.6 and 11.4 years respectively.

Results of the binary logistic regression analysis for an association between heart dis ease and the risk factors, age, sex, breed and diabetes are shown in Table 6. Diabetes was identified as a significant risk factor $(\mathrm{P}=0 \cdot 01)$ with cats suffering from diabetes being 10.4 times more likely to have heart disease (95 per cent CI from 1.8 to $61 \cdot 2$ ). There was no association of heart disease with sex or breed and age did not have any significant effect on the risk of heart disease.

Table 7 similarly shows that the only significant risk factor $(\mathrm{P}=0.002)$ associated with mortality was diabetes. Cats with diabetes were 3.4 times more likely to die (95 per cent CI $1 \cdot 1$ to $10 \cdot 6$ ).

Examination of the distribution of the survival times of cats following recruit ment to the study indicated that for con trols, 50 per cent did not survive more than 718 days, whereas for diabetics, 50 per cent did not survive more than 385 days. The box plot of the survival times by diabetic category are shown in Fig 1 . Multivariate regression analysis of the sur vival times indicated that sex and breed did not influence the survival times, whereas age and diabetes did, as shown in Table 8. Diabetic cats had significantly lower survival times $(\mathrm{P}=0.002)$ than con trols and as age increased, the survival time of cats decreased significantly $(\mathrm{P}=0 \cdot 004)$.

Table 5. Number of diabetic cats (cases) and non-diabetic cats (controls) in the case-control analyses classified according to the categorical variables investigated in the study

$\begin{array}{lcrr}\text { Variable } & \text { Level } & & \text { Diabetic } \\ & & \text { Cases } & \text { Controls } \\ \text { Heart disease } & \text { No } & 14 & 55 \\ \text { Survival } & \text { Yes } & 5 & 2 \\ \text { Sex } & \text { No } & 13 & 23 \\ \text { Breed } & \text { Yes } & 6 & 34 \\ & \text { Memale neuter } & 7 & 21 \\ & \text { Male neuter } & 12 & 36 \\ & \text { Domestic longhair } & 4 & 13 \\ & \text { Domestic shorthair } & 15 & 44\end{array}$

Table 6. Results from the multivariate binary logistic regression analysis showing the odds ratios, 95 per cent CI and significance (LRT P values) associated with the risk of heart disease for each of the categorical variables sex, breed and diabetes after adjustment for age of cat

\begin{tabular}{|c|c|c|c|c|}
\hline Predictor & Odds ratio & Lower 95 per cent $\mathrm{Cl}$ & Upper 95 per cent $\mathrm{Cl}$ & LRT P value \\
\hline Age (years) & 0.92 & 0.69 & $1 \cdot 24$ & 0.50 \\
\hline \multicolumn{5}{|c|}{ Sex (referent group FN) } \\
\hline $\mathrm{MN}$ & 1.93 & $0 \cdot 28$ & $13 \cdot 22$ & 0.60 \\
\hline \multicolumn{5}{|c|}{ Breed (referent group DLH) } \\
\hline DSH & 1.93 & 0.28 & $13 \cdot 22$ & 0.57 \\
\hline \multicolumn{5}{|c|}{ Diabetes (referent group NO) } \\
\hline YES & $10 \cdot 38$ & $1 \cdot 76$ & $61 \cdot 18$ & 0.01 \\
\hline
\end{tabular}

Table 7. Results from the multivariate binary logistic regression analysis showing the odds ratios, 95 per cent $C$ and significance (LRT $P$ values) associated with the risk of death for each of the categorical variables sex, breed and diabetes after adjustment for age of cat

\begin{tabular}{|c|c|c|c|c|}
\hline Predictor & Odds ratio & Lower 95 per cent $\mathbf{C I}$ & Upper 95 per cent $\mathbf{C l}$ & LRT $P$ value \\
\hline Age (years) & $1 \cdot 15$ & 0.95 & $1 \cdot 38$ & $0 \cdot 15$ \\
\hline \multicolumn{5}{|c|}{ Sex (referent group FN) } \\
\hline $\mathrm{MN}$ & 0.66 & 0.22 & 1.95 & 0.45 \\
\hline \multicolumn{5}{|c|}{ Breed (referent group DLH) } \\
\hline DSH & 0.53 & 0.14 & 1.98 & 0.35 \\
\hline \multicolumn{5}{|c|}{ Diabetes (referent group NO) } \\
\hline YES & 3.39 & 1.08 & $10 \cdot 60$ & 0.036 \\
\hline
\end{tabular}

CI Confidence interval, LRT Likelihood ration test, FN Female neutered, MN Male neutered, DLH Domestic longhair, DSH Domestic shorthair

\section{DISCUSSION}

The epidemiological features of diabetes mellitus in this group of cats from first opinion practice are in keeping with those reported elsewhere with a notable pre dominance of males (Panciera and others 1990, Peterson 1998, Rand and Marshall 2004, Rand and others 2004). None of the cats were Burmese.

The present study is flawed because it addresses a small sample of diabetic cats seen at a single centre. It is also a retrospec tive study and retrospective studies should always be interpreted with caution.

A matched case control design was chosen for this study in order to derive the maximum amount of meaningful infor mation from a small number of diabetic cats. Three controls were chosen from the same practice as the cases; they were matched for age, breed and sex to each index case of diabetes. Each control case was enrolled into the study having been seen for a routine vaccination or a new epi sode of disease within a short time period 


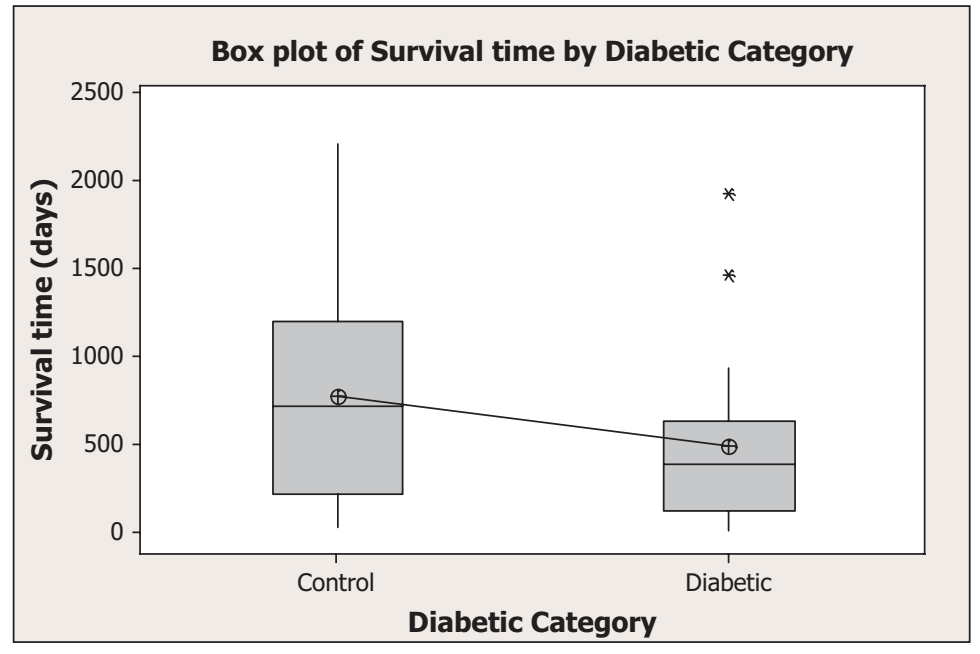

FIG 1. Box plot illustrating the difference in distribution of the survival times in days since recruitment to the study of control and diabetic cats. * represents outliers

before or after the index case. This design was chosen to attempt to select controls that did not differ systematically from the cases except for the absence of diabetes and to avoid over representation of ani mals with other chronic disease processes in the control population.

The most important finding from this study is that heart failure was frequent in this sample of cats with diabetes mellitus. Moreover, all cats with heart failure died or were euthanased soon after the develop ment of this condition. The findings from the case control analyses have clearly iden tified diabetes as the one significant risk factor associated with both heart disease and mortality in this primary first opinion practice. Age, breed and sex of the cat were not identified as risk factors. Diabetic cats were 10.4 times ( 95 per cent CI 1.8 to 61.2) more likely to have heart disease and 3.4 times (95 per cent CI $1.1 \mathrm{t}$ 10.6) more likely to die than their age matched and breed matched controls. These results are consistent with diabetic cats being more predisposed to heart dis ease, which in turn increases the risk of mortality. The survival time of diabetic cats from point of diagnosis did differ significantly from their controls and depended on the age of the cat. The median survival time of diabetic cats was just over one year (385 days) com pared with almost two years (718 days) for their controls.

Of the six diabetic cats in this study identified as having heart failure, five of the six had a pleural effusion and two of the six had ascites, a finding, which is relatively uncommon in cats with heart failure. Three of these diabetic cats were found to have very enlarged left atria on
Table 8. Results from the multivariate survival time (days) analysis showing the regression coefficients, 95 per cent Cls and significance ( $P$ values) associated with each of the categorical variables sex, breed and diabetes after adjustment for age of cat and fitting a Weibull distribution taking account of right censoring

\begin{tabular}{|c|c|c|c|c|}
\hline Predictor & Coefficient & Lower 95 per cent $\mathrm{Cl}$ & Upper 95 per cent $\mathbf{C I}$ & $P$ value \\
\hline Shape & 1.0219 & 0.7787 & $1 \cdot 3411$ & \\
\hline Age (years) & -0.1877 & -0.3168 & -0.0586 & 0.004 \\
\hline \multicolumn{5}{|c|}{ Sex (referent group FN) } \\
\hline $\mathrm{MN}$ & -0.1139 & -0.8749 & 0.6472 & 0.769 \\
\hline \multicolumn{5}{|c|}{ Breed (referent group DLH) } \\
\hline DSH & 0.4162 & -0.4429 & $1 \cdot 2754$ & 0.342 \\
\hline \multicolumn{5}{|c|}{ Diabetes (referent group NO) } \\
\hline YES & $-1 \cdot 1052$ & $-1 \cdot 7899$ & -0.4206 & 0.002 \\
\hline
\end{tabular}

CI Confidence interval, FN Female neutered, MN Male neutered, DLH Domestic longhair, DSH Domestic shorthair echocardiography; in the other two cases where echocardiography was permitted, the findings were also compatible with heart failure. In addition, three of these cats had serious dysrhythmias docu mented by electrocardiography (ECG; atrial fibrillation, ventricular premature complexes and third degree heart block). A fourth cat (case 7) also had a dysrhyth mia audible on auscultation in the latter stages of the illness, ECG evaluation of the rhythm was not sanctioned by the owner so the exact nature of this rhythm disturbance remains obscure. One other cat (case 10) exhibited sinus bradycardia.

In the past, particularly before the advent of echocardiography, many cats with heart failure were probably misdiag nosed, because the most frequent signs of heart failure recognised in other veterinary species, such as coughing and tachycar dias, are infrequently found in cats with heart failure. If a cat has a pleural effusion, cardiac auscultation is often very challeng ing so that heart murmurs or gallop sounds may not be identified with ease. Moreover, until fairly recently, cats with pleural effusions were often designated as having idiopathic effusions or other thoracic disease without performing echo cardiographic studies. These observations may explain why heart failure has not been identified as a frequent complication of diabetes mellitus in cats.

The forms of heart disease and failure, which the cats in this study exhibited, were by no means identical; some showed signs compatible with hypertrophic cardio myopathy, whereas others showed signs principally indicating right sided heart failure. This heterogeneity in clinical ap pearance suggests that diabetes mellitus probably does not cause cardiac disease in cats directly or simply. However, in this species, as in the human sufferer, diabetes mellitus may promote or exacerbate exist ing heart disease. It is unfortunate that sys temic blood pressures were not measured in these diabetic cats because if hyperten sion were present it might offer one expla nation for the development of heart failure. Many human diabetics are hyper tensive. On the contrary, limited data sug gest that hypertension is not common in feline diabetics (Sennello and others 2003). 
It is possible that one or more of these diabetic cats with heart failure might have had acromegaly, a disease which is known to cause diabetes and heart failure in cats (Peterson and others 1990). However, the usual principal sign of acromegaly is uncontrolled hyperglycaemia in spite of insulin dosage exceeding 20 iu per day (Norman and Mooney 2000, Peterson 2004). The maximum dose of insulin given to a cat in this study was $12 \mathrm{iu}$ per day. Acromegaly is also much less common than uncomplicated diabetes mellitus. However, in none of the cats in the present study was insulin like growth factor measured and no other tests were used to deliberately seek out cases of acromegaly.

One or more of the cats with diabetes and heart failure could have had hyperthy roidism, a disease which is very common in older cats and which sometimes can cause heart failure (Mooney and Petersen 2004). Diabetic cats with known hyper thyroidism were deliberately excluded from this study in the recruitment criteria. Signs of thyroid enlargement were regu larly sought by clinical examination of the diabetic cats and thyroid assays were performed in 10 cats during the course of their illness, including three of those cats found to develop heart failure. None of these cats was diagnosed as suffer ing from hyperthyroidism but, because routine thyroid monitoring was not performed in all cases, this possibility cannot be excluded.

Studies of the prognosis and outcome for cats with diabetes have been relatively few. However, if we examine some of these publications, most of which describe cases from secondary or tertiary referral hospitals, we discover that in common with the observations in the present study, heart disease may have been present in a considerable number of these diabetic cats. For instance, in a large study of 104 cats with diabetes (Crenshaw and Peterson 1996), concurrency between dia betes mellitus and heart disease was not remarked upon as an important finding and yet heart murmurs (19 of 104) and gallop rhythms (seven of 104) were fre quently identified during physical exami nation of these cats. Additionally, these authors reported cardiac enlargement in
14 of 52 cases ( 27 per cent) where a chest radiograph was taken. In another much smaller study, which investigated the effects of diet on glycaemia in 16 diabetic cats (Nelson and others 2000), at the time of entry into the study two cats had heart murmurs and another two cats exhibited audible cardiac gallop sounds. A recent publication, which focused on cats in an emergency hospital, also reported heart murmurs and gallop sounds in a signifi cant proportion of cats with diabetes seen in crisis situations (Koenig and others 2004). Congestive heart failure was re corded in five of 17 cats with hypergly caemic hyperosmolar syndrome, one of 33 cats with diabetic ketoacidosis and six of 78 cats with uncomplicated diabetes mellitus. Again the authors did not recog nise or report an overt relationship between diabetes mellitus and heart fail ure. However, in two other retrospective studies of diabetes mellitus, heart disease or heart failure were not reported at all in diabetic cats (Kraus and others 1997, Goossens and others 1998).

In human beings, diabetes mellitus is an independent risk factor for the develop ment of heart disease and heart failure. The exact relationship between diabetes and cardiovascular disease in people is complex. Diabetes causes an atherogenic dyslipidaemia, which leads to accelerated coronary artery disease and myocardial ischaemia. A specific myocardial disease, diabetic cardiomyopathy, is also reported. Hypertension, an autonomic neuropathy leading to decreased cardiac vagal tone, glycation of myocardial proteins and endothelial dysfunction may all contribute to the development of diabetic cardiomy opathy, but human diabetics are also fre quently obese and chronically physically inactive and this lifestyle appears to con tribute to both diabetes and heart disease (Julu 1993, Grundy and others 1999, McNally and Lawrence 2003, Almdal and others 2004, Bell 2004, Bertoni and others 2004, Nichols and others 2004). Cardiovascular diseases are listed as the cause of death in about 65 per cent of per sons with diabetes (Grundy and others 1999).

Diet and exercise probably are impor tant in the aetiology of diabetes in cats, as they are in people (Rand and Marshall
2005). Eighty years ago, Joslin drew atten tion to a link between diabetes, obesity and cardiovascular disease in people (Joslin 1927). A similar link may exist in the cat. The implications of these find ings for both veterinary and compara tive medicine certainly warrant further investigation.

\section{Acknowledgements}

We would like to thank the nursing and veterinary staff at Barton Veterinary Hos pital for their dedication in the care of these patients. We also thank the secretar ial and reception staff at Barton Veterinary Hospital, particularly Angela Francis, who tirelessly interrogated our computer records for this study.

The active support and encouragement of CVS (UK) Ltd, owners of The Barton Veterinary Hospital, is gratefully acknowl edged.

CL did much of this work whilst in receipt of a Blue Skies Research Grant from the RCVS Trust.

\section{References}

Almdal, T., Scharling, H., Jensen, J. S. \& Vestergaard, H. (2004) The independent effect of type 2 diabetes mellitus on ischaemic heart disease, stroke, and death: a population based study of 13,000 men and women with 20 years of follow up. Archives of Internal Medicine 164, 14221426

BeLL, D. S. H. (2004) Heart failure: a serious and com mon comorbidity of diabetes. Clinical Diabetes 22, 6165

Bertoni, A. G., Hundley, W. G., Massing, M. W., Bonds, D. E. \& BuRKE, G. L. (2004) Heart failure preva lence, incidence, and mortality in the elderly with diabetes. Diabetes Care 27, 699703

Crenshaw, K. L. \& Peterson, M. E. (1996) Pretreat ment clinical and laboratory evaluation of cats with diabetes mellitus: 104 cases (1992 1994). Journal of the American Veterinary Medical Asso ciation 209, 943948

Goossens, M. M. C., Nelson, R. W., Feldman, E. C. \& Griffey, S. M. (1998) Response to insulin treat ment and survival in 104 cats with diabetes mel litus (1985 1995). Journal of Veterinary Internal Medicine 12, 16

Grundy, S. M., Benjamin, I. J., Burke, G. L., Chait, A., ECKel, R. H., Howard, B. V., Mitch, W., SMith, S. C. J. \& SowERS, J. R. (1999) Diabetes and cardiovas cular disease: a statement for healthcare profes sionals from the American Heart Association. Circulation 100, 11341146

JACOBS, G. \& KNIGHT, D. H. (1985) M mode echocardio graphic measurements in non anaesthetised healthy cats: effects of body weight, heart rate, and other variables. American Journal of Veteri nary Research 46, 17051711

JosLIN, E. P. (1927) Arteriosclerosis in diabetes. Annals of Clinical Medicine 5, 10611079

Jutu, P. O. O. (1993) Vagolytic effect of diabetes mel litus. Brain 116, 485492

Koenig, A., Drobatz, K. J., Beale, A. B. \& King, L. G. (2004) Hyperglycaemic, hyperosmolar syndrome in feline diabetics: 17 cases (1995 2001). Journal of Veterinary Emergency and Critical Care 14, 3040 
Kraus, M. S., Calvert, C. A., Jacobs, G. J. \& Brown, J. (1997) Feline diabetes mellitus: a retrospective mortality study of 55 cats (1982 1994). Journal of the American Animal Hospital Association 33, 107111

Lister, A. L. \& Buchanan, J. W. (2000) Measurement of the normal feline cardiac silhouette on thoracic radiographs. Journal of the American Veterinary Medical Association 216, 210

McNally, P. G. \& Lawrence, I. G. (2003) Diabetic auto nomic neuropathy and the cardiovascular system. In: Heart Disease and Diabetes. Ed M. Fisher. Martin Dunitz, London and New York. pp 3564

Mooney, C. T. \& Petersen, M. E. (2004) Feline hyper thyroidism In: BSAVA Manual of Small Anima Endocrinology. 3rd edn. Eds C. T. Mooney and M. E. Peterson. British Small Animal Veterinary Association, Gloucester, UK. pp 95111

Nelson, R. W., Scott Moncrieff, J. C., Feldman, E. C., DeVries Concannon, S. E., Kass, P. H., Davenport, D. J., Kiernan, C. T. \& Neal, L. A. (2000) Effect of dietary insoluble fiber on control of glycaemia in cats with naturally acquired diabetes mellitus. Journal of the American Veterinary Medical Asso ciation 216, 10821088

Nichols, G. A., GULION, C. M., Koro, C. E., Ephross, S. A. \& Brown, J. B. (2004) The incidence of conges tive heart failure in type 2 diabetes. Diabetes Care 27, 18791884

ORMAn, E. J. \& MoOnEy, C. T. (2000) Diagnosis and management of diabetes mellitus in five cats with somatotrophic abnormalities. Journal of Feline Medicine and Surgery 2, 183190

ANCIERA, D. L., Thomas, C. B., EICKER, S. W. \& AtKins, C. E. (1990) Epizootiologic patterns of diabetes mellitus in cats: 333 cases (1980 1986). Journal of the American Veterinary Medical Association 197, 15041508

ETERSON, M. E. (1998) Feline diabetes mellitus. In: BSAVA Manual of Small Animal Endocrinology. 2nd edn. Eds A. G. Torrance and C. T. Mooney. British Small Animal Veterinary Association, Glou cester, UK. pp 97102

ETERSON, M. E. (2004) Acromegaly. In: BSAVA Manual of Small Animal Endocrinology. 3rd edn. Eds C. T. Mooney and M. E.Peterson. British Small Animal Veterinary Association, Gloucester, UK. pp 187192

eterson, M. E., Taylor, R. S., Greco, D. S., Nelson, R. W., Randolph J. F., Foodman, M. S., Moroff, S. D. MorRIson, S. A. \& LotHrop, C. D. (1990) Acromeg aly in 14 cats. Journal of Veterinary Internal Med icine 4, 192201
Pipers, F. S., Reef, V. \& Hamlin, R. L. (1979) Echocar diography in the domestic cat. American Journal of Veterinary Research 40,882 886

RAND, J. S. \& MARSHALL, R. (2004) Feline diabetes mel litus. In: BSAVA Manual of Canine and Feline Endocrinology. 3rd edn. Eds C. T. Mooney and M. E. Peterson. British Small Animal Veterinary Association, Gloucester, UK. pp 129141

RAND, J. S. \& MARShaLL, R. (2005) Understanding feline diabetes mellitus: pathogenesis and man agement. Waltham Focus 15, 511

Rand, J. S., Fleeman, L. M., Farrow, H. A., Appleton D. J. \& Lederer, R. (2004) Canine and feline diabetes mellitus: nature or nurture? The Journal of Nutri tion 134, 2072S 2080S

Sennello K. A., Schulman R. L., Prosek R. \& Siegel A. M. (2003) Systolic blood pressure in cats with diabe tes mellitus. Journal of the American Veterinary Medical Association 223, 198201

Sisson, D. D., KnIGht, D. H., HelsinkI, C., Fox, P. R., Bond, B. R., Harpster, N. K., Moise, N. S., Kaplan, P. M. Bonagura, J. D., Czamecki, G. \& Schaeffer, D. J. (1991) Plasma taurine concentrations and M mode echocardiographic measures in healthy cats and cats with dilated cardiomyopathy. Journal of Veteri nary Internal Medicine 5, 232238 